\title{
Paspalum (Poaceae) no Rio Grande do Norte, Brasil
}

\author{
Paspalum (Poaceae) in Rio Grande do Norte, Brazil
}

\author{
Regina Célia de Oliveira ${ }^{1,4}$, Suzi Helena de Santana ${ }^{1}$, Anádria Stéphanie da Silva ${ }^{1}$, \\ Jefferson Rodrigues Maciel ${ }^{2}$ \& José Francisco M. Valls ${ }^{1,3}$
}

\begin{abstract}
Resumo
Paspalum L. (Poaceae) apresenta elevada riqueza e importância econômica no Brasil. Diante da importância de estudos regionalizados para ampliar o conhecimento taxonômico das espécies e atualizar a lista da flora do Brasil, o presente trabalho descreve o gênero e as espécies de Paspalum do estado do Rio Grande do Norte. Foram realizadas coletas por quatro anos em todas as regiões fitogeográficas do Rio Grande do Norte e levantamento em herbários com coleções representativas da flora local. O estado de conservação das espécies foi avaliada segundo critérios regionais da IUCN. Foram registradas 16 espécies de Paspalum no Rio Grande do Norte. Paspalum carinatum Humb. \& Bonpl. ex Flüggé, P. gardnerianum Nees e P. pumilum Nees são consideradas vulneráveis no estado do Rio Grande do Norte, pela pressão antrópica sobre os ambientes em que ocorrem, porém, não são ameaçadas quando avaliadas em escala global. Com base na análise de populações no campo e em cultivo, propõe-se a sinonimização de $P$. pleostachyum Döll sob $P$. ligulare Nees. Ao contrário do que está difundido na literatura, justifica-se a preferência de utilização do nome Paspalum crassum Chase sobre P. tumidum Kuhlm. O trabalho inclui chave para identificação das espécies, descrições, comentários taxonômicos e nomenclaturais, informações sobre distribuição e grau de ameaça regional, bem como comentários ecológicos e ilustrações.

Palavras-chave: gramíneas, conservação, Região Nordeste do Brasil, Panicoideae, taxonomia.
\end{abstract}

\begin{abstract}
Paspalum L. (Poaceae) has high species richness and economic importance in the Brazilian flora. Given the importance of regional studies to increase taxonomic knowledge of the species and update the flora of Brazil's list, this study aims to describe the genus and species of Paspalum from Rio Grande do Norte, as part of a larger Flora of Rio Grande do Norte project. Collections were made in all the phytogeographic regions of Rio Grande do Norte during the last four years, and a survey was done of the herbaria with representative collections of local flora. The conservation status of the species was evaluated according to IUCN regional categories. We recorded 16 species of Paspalum in Rio Grande do Norte. Paspalum carinatum Humb. \& Bonpl. ex Flüggé, $P$. gardnerianum Nees and P. pumilum Nees are considered vulnerable in Rio Grande do Norte state, due to manmade pressures on the environment where they occur. However, they are not threatened when evaluated on a global scale. Based on an analysis of populations in the field and under cultivation, we propose to synonymize P. pleostachyum Döll under P. ligulare Nees. Contrary to what is found in the literature, the preference for using the name Paspalum crassum Chase over P. tumidum Kuhlm. is justified. This work includes a key for species identification, morphological descriptions, taxonomic and nomenclatural comments, information on distribution and regional-threat criteria, as well as ecological aspects and illustrations of the species.
\end{abstract}

Key words: grasses, conservation, Northeast region of Brazil, Panicoideae, taxonomy.

\section{Introdução}

Poaceae é uma das mais ricas famílias de plantas, com aproximadamente 800 gêneros e 10.000 espécies (Watson \& Dalwitz 1992) economicamente importantes, pois incluem cereais, forrageiras e bambus.
Há várias propostas de subdivisão de Poaceae em subfamílias, e Panicoideae foi reconhecida já nas primeiras propostas de classificação infrafamiliar (Longhi-Wagner 2012). As Panicoideae são caraterizadas pela articulação da ráquila e pedicelo

\footnotetext{
'Universidade de Brasília, Inst. Biologia, Programa de Pós-graduação em Botânica, C.P. 04457, 70910-970, Brasília, DF, Brasil.

${ }^{2}$ Jardim Botânico do Recife, km 7,5 da BR 232 s/n, 50000-230, Recife, PE, Brasil.

${ }^{3}$ Embrapa Recursos Genéticos e Biotecnologia, Parque Estação Biológica, Av. W5 Norte (final), C.P. 02372, 70770-900 Brasília, DF, Brasil.

${ }^{4}$ Autor para correspondência: reginacelia@unb.br
} 
localizada abaixo das glumas e dois antécios, o inferior masculino ou neutro e o superior hermafrodita (Longhi-Wagner 2012). Inclui 3.270 espécies (GPWG 2001) e 785 espécies, seis subespécies e 38 variedades no Brasil (Filgueiras et al. 2013).

Paspalum L. se caracteriza pelas inflorescências parciais racemiformes, com espiguetas planoconvexas distribuídas unilateralmente sobre a ráquis, com o dorso do lema superior em posição adaxial e, salvo algumas exceções, pela ausência da gluma inferior (Oliveira \& Valls 2008). Compreende cerca de 330 espécies distribuídas nas regiões tropicais e temperadas das Américas, algumas ocorrendo na África e Ásia (Zuloaga \& Morrone 2005). Para o Brasil, Valls \& Oliveira (2012) listaram 204 espécies, entre as quais 74 endêmicas, sendo 18 espécies de Paspalum para o Rio Grande do Norte.

Poucos autores agruparam as espécies de Paspalum em subgêneros e secções. Os subgêneros mais aceitos são Paspalum, Ceresia e Anachyris (Denham et al. 2002; Hojsgaard et al. 2008). As secções mais comumente utilizadas são Paspalum, Diplostachys (Steud.) Tvelev (com 3/4 das espécies), Pterolepidium Pilg., Erianthum Pilg., Eriolepidium Pilg., Moenchia (Chase) Pilg., Biaristata Filg. \& Davidse, Ceresia (Pers.) Nees e Anachyris (Nees) Pilg. Entretanto, a maior parte das publicações taxonômicas prefere associar as espécies de Paspalum a grupos informais, baseados somente em caracteres morfológicos. Todavia, os limites e a circunscrição desses grupos variam entre os trabalhos de Chase (1929), Swallen (1967), Barreto (1974) e muitos outros, refletindo apenas semelhanças morfológicas a uma espécie central, escolhida de forma arbitrária, sem conotação filogenética.

Devido ao grande potencial forrageiro das espécies de Paspalum, vários trabalhos com abordagens distintas têm sido conduzidos, estando disponível na literatura vasta informação citogenética, reprodutiva e filogenética. No entanto, ainda não há uma monografia de Paspalum para o Brasil, embora uma parte significativa de suas espécies esteja coberta pela revisão publicada para a América do Sul Meridional (Zuloaga \& Morrone 2005) e pela revisão das espécies norte-americanas (Chase 1929).

Informações sobre as espécies de Paspalum no Rio Grande do Norte são incipientes, mas relatos de coletas de gramíneas no estado não são recentes (Swallen 1934 e Luetzelburg, apud Ducke 1959). Nos anos de 1920-1921, Luetzelburg percorreu áreas de Pernambuco, Paraíba, Rio Grande do Norte e Ceará (Paiva 2003), deixando um legado de coletas de Poaceae e Cyperaceae (Ducke 1959), em parte localizado no herbário EAC (Thiers 2013). Posteriormente, Swallen (1934) reuniu uma importante coleção de amostras de gramíneas provenientes do Maranhão, Piauí, Ceará e Rio Grande do Norte, as quais estão depositadas no herbário US.

A literatura sobre Paspalum na Região Nordeste do Brasil é escassa, destacando-se, pela citação de um número relevante de espécies do gênero, as Gramíneas da Bahia (Renvoize 1984) e os trabalhos de Maciel et al. (2009a, b), que tratam as espécies de Paspalum de Pernambuco e seus padrões de distribuição no estado. Maciel \& Alves (2011) documentaram a ocorrência de oito espécies de Paspalum na Serra de Itabaiana, em Sergipe. Para o Rio Grande do Norte, o único trabalho que tratou as espécies de Poaceae trata-se de Ferreira et al. (2009), realizado na Estação Ecológica do Seridó, onde foi documentada a presença de cinco espécies de Paspalum.

Diante da importância de estudos regionalizados para ampliar o conhecimento taxonômico das espécies e atualizar a lista da flora do Brasil, o presente trabalho teve como objetivo realizar o levantamento das espécies de Paspalum do Rio Grande do Norte, fornecer uma chave para identificação das espécies, ilustrações, dados ecológicos, de distribuição geográfica, além de comentários taxonômicos e nomenclaturais.

\section{Material e Métodos}

$\mathrm{O}$ estudo foi baseado em coletas realizadas por quatro anos, que cobriram todas as regiões fitogeográficas do Rio Grande do Norte em diferentes estações do ano e em análises de herbário. O material coletado foi depositado nos herbários MOSS e UFRN e foram analisados os herbários EAC, IPA, UB e UFRN (Thiers 2013). Duplicatas foram enviadas a diversos herbários nacionais.

Aspectos das preferências ambientais, distribuição geográfica e potencial forrageiro foram obtidos a partir dos dados de herbário, de observações in situ das populações e de bancos de dados disponíveis na internet. Esses dados foram complementados com a literatura disponível sobre o gênero (Barreto 1974; Chase 1929; Denham 2005; Oliveira \& Valls 2001; Zuloaga \& Morrone 2005, entre outros).

As coordenadas geográficas indisponíveis foram resgatadas a partir da coordenada da sede do município ou da própria localidade onde a amostra foi anteriormente coletada. Dados de distribuição 
geográfica no Brasil foram obtidos de Valls \& Oliveira (2012).

No material examinado foram citadas, preferencialmente, as coletas mais recentes e de localidades distintas. Os materiais selecionados para ilustração são aqueles mais representativos da espécie e, para as sinonímias, foram selecionados indivíduos que representam os extremos de variação da espécie e o intermediário.

A descrição morfológica das espécies seguiu a terminologia apresentada por Longhi-Wagner et al. (2001) e a dos estados de caráter, como pilosidade e forma das estruturas, baseou-se em Radford (1986).

O grau de ameaça das espécies foi definido seguindo os critérios da IUCN (2003), devendo ser considerado, entretanto, apenas em nível regional.

\section{Resultados e Discussão}

Tratamento taxonômico

\section{Paspalum L.}

Plantas anuais ou perenes, cespitosas, decumbentes ou estoloníferas, com ou sem rizomas; prefoliação convoluta ou conduplicada. Bainhas foliares delgadas ou infladas, inteiras ou fibrosas, glabras a híspidas; colo glabro ou piloso, sem lígula externa; lâminas lineares a ovallanceoladas, planas, convolutas ou conduplicadas, geralmente agudas, base reta ou atenuada, glabras ou pilosas; lígula membranosa. Inflorescência com 1-muitos ramos unilaterais espiciformes, alternos, conjugados ou solitários; inflorescências axilares presentes ou ausentes; ráquis áptera ou alada. Espiguetas com 2 antécios, 1-floras, acrótonas, sem cerdas involucrais, solitárias ou pareadas, caindo isoladas, plano convexas ou côncavo convexas, glabras ou pilosas; glumas múticas, ápice não cristado; gluma inferior ausente, ou raramente presente em algumas espiguetas, então diminuta (ver $P$. vaginatum); gluma superior geralmente subigual à espigueta, raramente ausente $(P$. gardnerianum), adaxial à ráquis, aguda ou obtusa, glabra ou pilosa, tricomas não uncinados; antécio inferior neutro ou raramente masculino; antécio superior com flor bissexuada, cartáceo ou coriáceo, branco-esverdeado, estramíneo ou castanhoescuro; lema não rugoso, papiloso ou não, glabro ou pouco piloso, mútico, não cristado no ápice, sem alas ou cicatrizes na base, de igual consistência em toda a extensão, margens envolvendo brevemente a pálea; pálea áptera. Estames 3. Cariopse elíptica a hemisférica.

Foi confirmada a ocorrência de 16 espécies de Paspalum no Rio Grande do Norte. Valls \& Oliveira (2012) citaram a ocorrência de 18 espécies para o Rio Grande do Norte. Entretanto, no presente trabalho, está sendo proposta a sinonimização de Paspalum pleostachyum com $P$. ligulare e a ocorrência de $P$. decumbens Stapf. não foi confirmada.

\section{Chave para as espécies de Paspalum L. ocorrentes no Rio Grande do Norte}

1. Espiguetas escutiformes

15. P. scutatum

1'. Espiguetas ovais, obovais, orbiculares, amplamente oboval, elíptico-oboval ou elípticas.

2. Gluma superior presente, alada, com bordos fimbriados 6. P. fimbriatum

2'. Gluma superior ausente ou presente, áptera, com bordos inteiros.

3. Ambas as glumas ausentes; pedicelos com tricomas longos, dourados, com comprimento similar à espigueta

3'. Gluma inferior ausente, a superior presente; pedicelos glabros ou com tricomas curtos e hialinos, muito mais curtos que o comprimento da espigueta.

4. Inflorescências axilares presentes.

5. Plantas com rizomas e estolhos longos; colmos com 50-100 cm alt.

5'. Plantas sem rizomas e estolhos; colmos com até $35 \mathrm{~cm}$ alt.

6. Lâminas lanceoladas, 0,4-0,7 cm larg.; espiguetas $1,1 \times 1 \mathrm{~mm}$, obovais; gluma superior e lema inferior com tricomas não clavados ........... 1. P. arenarium

6'. Lâminas lineares, $0,1-0,3 \mathrm{~cm}$ larg.; espiguetas $1,5 \times 0,8 \mathrm{~mm}$ gluma superior e lema inferior com tricomas tricomas clavados 3. P. clavuliferum

4'. Inflorescências axilares ausentes.

7. Antécio superior castanho-escuro ou atro-purpúreo 11. P. melanospermum

7’. Antécio superior estramíneo. 
8. Bainha foliar inflada

14. P. repens

8'. Bainha foliar delgada.

9. Inflorescência com 1 ramo; espiguetas 4,9 mm compr.; gluma superior e lema inferior com tricomas alvos visíveis a olho nu

9'. Inflorescência com 2-40 ramos; espiguetas $1,5-3,5 \mathrm{~mm}$ compr., glabras ou com pilosidade não evidente a olho nu.

10. Bainha fibrosa quando velha, pilosa, os tricomas dourados, densos e visíveis a olho nu na base da bainha e formando um colar no ápice; antécio superior com 3 nervuras aparentes no lema

9. P. loefgrenii

10'. Bainha inteira, glabra ou pilosa, os tricomas hialinos concentrados apenas nas margens, não visíveis a olho nu, sem colar de tricomas no ápice; antécio superior sem nervuras aparentes. 11. Plantas estoloníferas.

12. Gluma superior 2-nervada; espiguetas amareladas, $1,5-1,9 \mathrm{~mm}$ compr.

12'. Gluma superior 3-5 nervada; espiguetas esverdeadas ou estramíneas, 2,7-3 mm compr. 16. P. vaginatum

11'. Plantas cespitosas ou decumbentes.

13. Ráquis alada, $2-3 \mathrm{~mm}$ larg.; gluma superior e lema inferior subcartáceos

5. P. crassum

13'. Ráquis áptera, 0,4-1 mm larg.; gluma superior membranácea ou cartilaginosa.

14. Inflorescência com 2 ramos subconjugados

11. P. pumilum

14'. Inflorescência com (4-) 9-40 ramos alternos.

15. Ráquis com tricomas longos nas margens; espiguetas 1,5-1,9 mm larg., orbiculares ou amplamente obovais

12. P. millegrana

15'. Ráquis com margens glabras ou escabras, sem tricomas longos; espiguetas $1-1,5 \mathrm{~mm}$ larg., elípticas 8. P. ligulare

1. Paspalum arenarium Schrad. in Schult., Mant. 2: 172.1824.

Fig. 1a.

Plantas perenes, decumbentes, $35 \mathrm{~cm}$ alt., com rizomas curtos; nós glabros. Bainhas foliares delgadas, inteiras, glabras ou pilosas, especialmente próximo às margens, tricomas hialinos, sem cílios marginais, sem colar de tricomas no ápice; lâminas 3,3-4 × 0,4-0,7 cm, lanceoladas, não estreitadas em direção à base, planas, hirsutas em ambas as faces; lígula ca. 0,2 mm. Inflorescência com 1 ramo de 2,5-5 cm compr.; inflorescências axilares presentes; ráquis ca. $0,1 \mathrm{~mm}$ larg., áptera, estramínea, glabra nas margens e axila; pedicelo com tricomas mais curtos que o comprimento da espigueta, hialinos. Espiguetas pareadas, $1,1 \times 1 \mathrm{~mm}$, estramíneas, com manchas douradas, obovais, obtusas; gluma inferior ausente; gluma superior áptera, com bordos inteiros, 3-nervada, levemente hirsuta, tricomas não visíveis a olho nu, sem tricomas clavados no ápice, sem cílios, membranácea; lema inferior 3-nervado, sem pálea, glabro ou levemente hirsuto em toda a superfície, membranáceo, não plicado; antécio superior $1 \times 0,9 \mathrm{~mm}$, estramíneo, oboval, liso, sem nervuras aparentes, glabro. Cariopse não disponível.
Material selecionado: Nísia Floresta, $6^{\circ} 05^{\prime} 16^{\prime \prime} \mathrm{S}$ e $36^{\circ} 07^{\prime} 22$ ”'W, VII.2006, R.C. Oliveira et al. 1750 (MOSS).

Habita locais antropizados com solos arenosos. Encontrada em floração de julho a setembro. Ocorre das Guianas até o Sul do Brasil (Zuloaga \& Morrone 2005), ao longo de toda a costa Atlântica.

Critérios regionais de ameaça segundo IUCN: LC (preocupação menor). Esta espécie é comum no litoral sul do Rio Grande do Norte, mas há registros de coletas também no município de Natal.

Paspalum arenarium é diferenciada das demais espécies pela gluma superior levemente hirsuta com manchas douradas e pela presença de inflorescências axilares. Segundo Silva et al. (1979) e Oliveira \& Valls (2001), o número de ramos da inflorescência em $P$. arenarium pode variar de 1-4.

2. Paspalum carinatum Humb. \& Bonpl. ex Flüggé, Gram. monog., Paspalum: 65.1810.

Fig. 1b

Plantas perenes, cespitosas, ca. $30 \mathrm{~cm}$ alt., sem rizomas; nós pilosos. Bainhas foliares delgadas, inteiras, tuberculado-hirsutas em especial na superfície dorsal, tricomas hialinos, sem cílios marginais, sem 


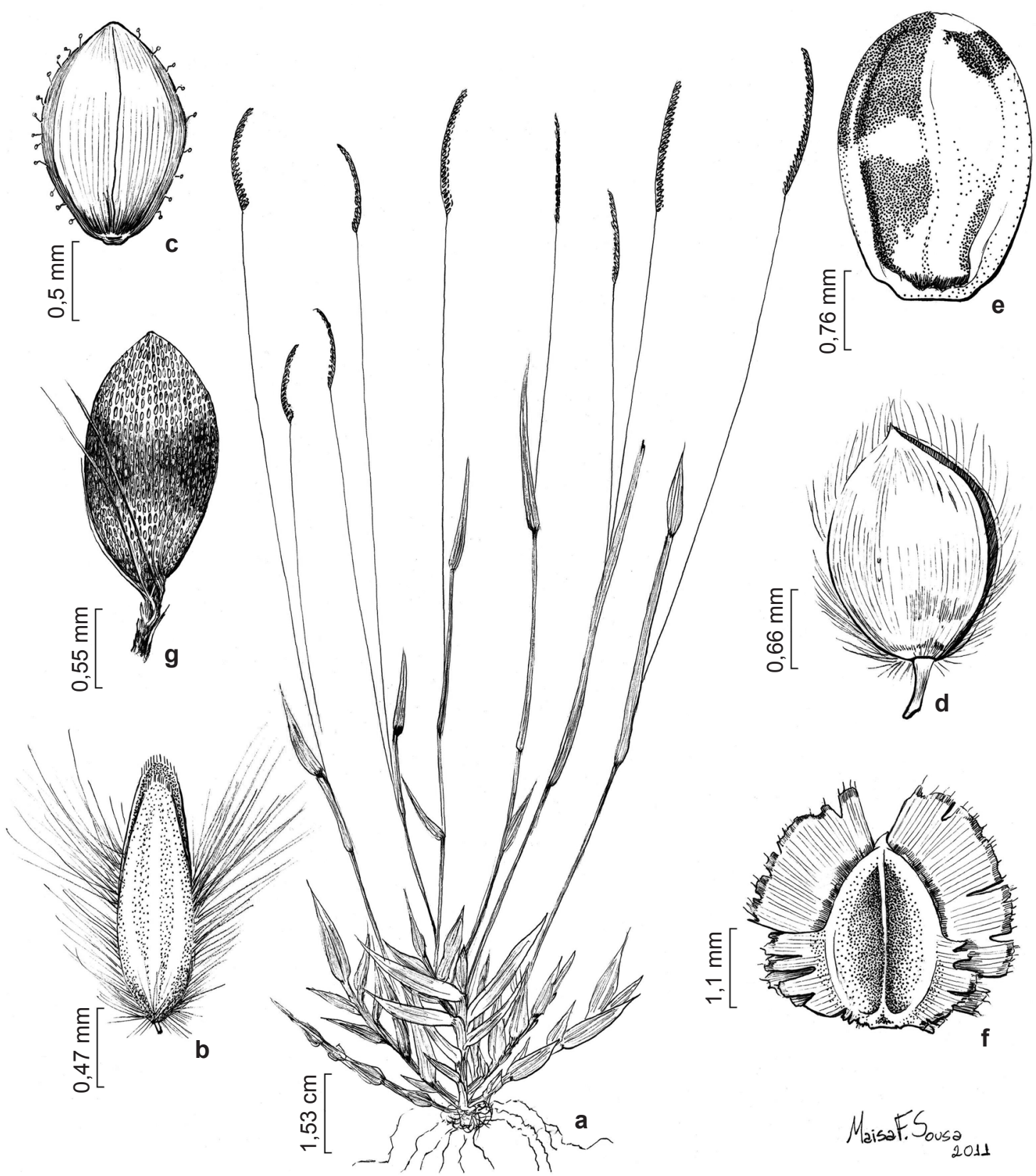

Figura 1 - a. Paspalum arenarium Schrad. - hábito. b. Paspalum carinatum Humb. \& Bonpl. ex Flüggé espigueta, vista ventral. c. Paspalum clavuliferum C. Wright - espigueta, vista dorsal. d. Paspalum conjugatum $\mathrm{P}$. J. Bergius - espigueta, vista dorsal. e. Paspalum crassum Chase - espigueta, vista dorsal. f. Paspalum fimbriatum Kunth - espigueta, vista ventral. g. Paspalum gardnerianum Nees - espigueta, vista dorsal e pedicelo. (a Oliveira et al. 1750; b Oliveira et al. 1760; c Oliveira et al. 1880; d Oliveira 883; e Oliveira et al. 2158; f Oliveira 1783; g Oliveira et al. 1759).

Figure 1 - a. Paspalum arenarium Schrad. - habit. b. Paspalum carinatum Humb. \& Bonpl. ex Flüggé - spikelet, ventral view. c. Paspalum clavuliferum C. Wright - spikelet, dorsal view. d. Paspalum conjugatum P. J. Bergius - spikelet, dorsal view. e. Paspalum crassum Chase - spikelet, dorsal view. f. Paspalum fimbriatum Kunth - spikelet, ventral view. g. Paspalum gardnerianum Nees spikelet, dorsal view and pedicel. (a Oliveira et al. 1750; b Oliveira et al. 1760; c Oliveira et al. 1880; d Oliveira 883; e Oliveira et al. 2158; f Oliveira 1783; g Oliveira et al. 1759). 
colar de tricomas no ápice; lâminas 9-15 × 0,05-0,09 $\mathrm{cm}$, filiformes, convolutas, tuberculado-hirsutas em ambas as faces; lígula ca. $1 \mathrm{~mm}$. Inflorescência com 1 ramo de $7 \mathrm{~cm}$ compr.; inflorescências axilares ausentes; ráquis em torno de 2,5 mm larg., alada, margens foliáceas encobrindo parcialmente as espiguetas, asas douradas, glabras; pedicelo com tricomas hialinos mais curtos que o comprimento da espigueta, hialinos. Espiguetas solitárias, 4,9 × 3 $\mathrm{mm}$, alvas a estramíneas, sem manchas, lanceoladas, obtusas; gluma inferior ausente; gluma superior áptera, com bordos inteiros, 3-nervada, tricomas adensandose progressivamente nos $2 / 5$ inferiores, visíveis a olho nu, glabra no ápice, sem tricomas clavados no ápice, sem cílios, membranácea; lema inferior 3-nervado, sem pálea, tricomas curtos e sedosos na base e longos e não clavados no $1 / 3$ restante, visíveis a olho nu, cartáceo, não plicado; antécio superior 3,1 $\times 0,9 \mathrm{~mm}$, estramíneo, liso, oblongo-lanceolado, sem nervuras aparentes, pubescente no ápice. Cariopse não disponível.

Ocorre em vegetação de Cerrado sobre solos arenosos. Encontrada em floração em julho. Ocorre na Nicarágua, Colômbia, Guiana, Venezuela, Brasil e Bolívia (Zuloaga \& Morrone 2005). No Brasil está distribuída em todas as regiões.

Material examinado: Ceará Mirim, $05^{\circ} 38^{\prime} 02^{\prime \prime} \mathrm{S}$ e $35^{\circ}$ 25'33"W, VII.2006, R. C. Oliveira et al. 1760 (MOSS).

Critérios regionais de ameaça segundo IUCN: VU (vulnerável no nível regional). Paspalum carinatum forma subpopulações (IUCN 2003) em áreas disjuntas de Cerrado, no Rio Grande do Norte, as quais ocorrem próximo ao litoral e, por isto, sofrem com o impacto imobiliário.

Paspalum carinatum é distinguida pelas lâminas foliares filiformes e espiguetas densamente pilosas, com tricomas alvos e longos, visíveis a olho nu.

3. Paspalum clavuliferum C. Wright, Anales Acad. Ci. Med. Habana 8: 203. $1871 . \quad$ Fig. 1c

Plantas anuais, cespitosas, 19-35 cm alt., sem rizomas; nós glabros. Bainhas foliares delgadas, inteiras, as basais pilosas, as distais glabras no dorso e com cílios no ápice, tricomas hialinos, sem colar de tricomas no ápice; lâminas 7-12,5 ×0,1-0,3 cm, lineares, não estreitadas em direção à base, planas, glabrescentes em ambas as faces; lígula ca. 1,5 $\mathrm{mm}$. Inflorescência com 1(-2) ramos de 2,5-4,2 cm compr.; inflorescências axilares presentes; ráquis 0,4 mm larg., áptera, estramínea, glabra; pedicelo com tricomas mais curtos que o comprimento da espigueta, hialinos. Espiguetas pareadas, 1,5 × 0,8 $\mathrm{mm}$, estramíneas, com manchas castanhas, elíptico- obovais; gluma inferior ausente; gluma superior áptera com bordos inteiros, 3-nervada, hirsuta, com tricomas claviformes no ápice, tricomas não visíveis a olho nu, sem cílios, membranácea; lema inferior 3-nervado, sem pálea, com poucos tricomas claviformes ou glabro, membranáceo, não plicado; antécio superior $1,5 \times 0,8 \mathrm{~mm}$, estramíneo, elípticooboval, tuberculado, sem nervuras aparentes, glabro. Cariopse $1,0 \times 0,9 \mathrm{~mm}$, oval.

Material selecionado: Serra Negra do Norte, 06 33 '55'S e $37^{\circ} 17^{\prime} 37^{\prime}$ 'W, V.2007, R. C. Oliveira et al. 1880 (MOSS).

Habita áreas sujeitas à inundação. Encontrada em floração e frutificação em maio. Ocorre do México até a Bolívia (Zuloaga \& Morrone 2005) e Brasil, onde há registros para as Regiões Nordeste, Centro-Oeste e Sudeste.

Critérios regionais de ameaça segundo IUCN: LC (preocupação menor).

Paspalum clavuliferum é distinguida pelos tricomas claviformes presentes no ápice da gluma superior e, em menor quantidade, no lema inferior. As diminutas espiguetas e as inflorescências axilares também a distinguem das demais espécies ocorrentes no estado do Rio Grande do Norte.

4. Paspalum conjugatum P.J. Bergius, Act. Helv. Phys.-Math. 7:129, pl. 8. 1762 . Fig. 1d

Plantas perenes, estoloníferas, 30-100 cm alt., sem rizomas; nós glabros. Bainhas foliares delgadas, inteiras, pilosas nas porções marginais especialmente no ápice, tricomas hialinos, sem colar de tricomas no ápice; lâminas 5,5-15,5 × 0,6-1 cm, lanceoladas, não estreitadas em direção à base, planas, pilosas ou glabras em ambas as faces; lígula ca. 0,3 mm. Inflorescência com 2-3 ramos de 8-12 cm compr.; inflorescências axilares ausentes; ráquis ca. $1 \mathrm{~mm}$ larg., com alas estreitas, esverdeada, glabra; pedicelo glabro. Espiguetas solitárias, 1,5-1,9 × 1,2-1,5 mm, amareladas, sem manchas, ovais ou elíptico-ovais, subagudas a apiculadas; gluma inferior ausente; gluma superior com bordos inteiros, 2-nervada, glabras no dorso, tricomas não visíveis a olho nu, sem tricomas clavados no ápice, margem longo-ciliada, membranácea; lema inferior 2-nervado, sem pálea, glabro, membranáceo, não plicado; antécio superior 1,4-1,7 × 1,2-1,4 mm, amarelado, elíptico-oval a oval, liso, sem nervuras aparentes, glabro. Cariopse não disponível.

Material selecionado: Mossoró, 5¹1'31''S e 37²0'40”'W, VI.1981, O.F. Oliveira 883 (MOSS). Parnamirim, 05'54'57'S e 35'15'46"W, VII.2006, R.T. Queiroz \& M. Zikán 597 (MOSS, UFRN). Touros, 5¹9'40"S e 35²7'30”W, IX.1981, O.F. Oliveira 2029 (MOSS). 
Espécie ruderal, encontrada vegetando sobre solos arenosos. Encontrada em floração de maio a setembro. Distribui-se desde o sul dos Estados Unidos até a Argentina (Zuloaga \& Morrone 2005).

Critérios regionais de ameaça segundo IUCN: LC (preocupação menor).

Paspalum conjugatum caracteriza-se pelo hábito estolonífero, as lâminas planas e laxas, inflorescências com dois ramos terminais conjugados e um, eventualmente, inserido logo abaixo, ráquis verde-oliva e pelas inúmeras espiguetas amareladas, ciliadas e 2-nervadas.

5. Paspalum crassum Chase, Contr. U.S. Natl. Herb. 17(3): 239. 1913. Paspalum tumidum Kuhlm., Arch. Jard. Bot. Rio de Janeiro 4: 349, t. 27. 1925.

Fig. 1e

Plantas anuais, eretas sem formar touceiras, às vezes decumbentes, $100-200 \mathrm{~cm}$ alt., sem rizomas; nós glabros. Bainhas foliares delgadas, inteiras, tuberculado-pilosas no dorso, tricomas hialinos, sem cílios marginais, sem colar de tricomas no ápice; lâminas 10-20 × 1,5-2,3 cm, lanceoladas, não estreitadas em direção à base, planas, glabras em ambas as faces; lígula $2 \mathrm{~mm}$. Inflorescência com 2-5 ramos de 3,5-10 cm compr.; inflorescências axilares ausentes; ráquis $2-3 \mathrm{~mm}$ larg., alada, esverdeada, glabra; pedicelo glabro. Espiguetas pareadas ou solitárias por aborto de uma das espiguetas, 2,8-3,5 × 2,1-2,3 mm, estramíneas ou arroxeadas, sem manchas, elípticas; gluma inferior ausente; gluma superior áptera, com bordos inteiros, 5-nervada, glabra, sem cílios, subcartácea; lema inferior 5-nervado, com pálea pouco desenvolvida, glabro, subcartáceo, não plicado; antécio superior 2,8-3,5 × 2,1-2,3 mm, estramíneo, elíptico, liso, sem nervuras aparentes, glabro. Cariopse 1,9 $\times$ $1,7 \mathrm{~mm}$, amplamente oboval.

Material examinado: Luís Gomes, estrada para Tigre de Cima, 6 ${ }^{\circ} 23^{\prime} 53^{\prime \prime} \mathrm{S}$ e $38^{\circ} 24^{\prime} 36^{\prime \prime} \mathrm{W}, \mathrm{V} .2008$, R. C. Oliveira et al. 2158 (MOSS).

Espécie aquática ou sub-aquática. Encontrada em floração em maio. Ocorre no México, El Salvador, Venezuela, Peru e Brasil (Zuloaga \& Morrone 2003). No Brasil, está restrita à Região Nordeste (Valls \& Oliveira 2012).

Critérios regionais de ameaça segundo IUCN: DD (dados insuficientes). Trata-se de uma espécie anual e aquática, inconspícua, o que torna a coleta e avaliação do tamanho das populações bastante difícil.

Zuloaga \& Morrone (2003), Soreng et al. (2003) e Hokche et al. (2008) consideraram os exemplarestipo de $P$. tumidum e $P$. crassum como variantes da mesma espécie, assim como é aceito no presente trabalho. Entretanto, esses autores consideraram prioritário o binômio $P$. tumidum, o que é um erro, já que o nome $P$. crassum foi proposto 12 anos antes.

Paspalum crassum, segundo Chase (1929), Hitchcock (1927) e Tovar (1993) pode apresentar maior amplitude morfológica do que a encontrada no Rio Grande do Norte, com altura variando entre 40 $200 \mathrm{~cm}$, lâminas com até $60 \mathrm{~cm}$ de comprimento, com 4-10 ramos unilaterais espiciformes na inflorescência.

No material do Rio Grande do Norte ocorre uma pálea muito curta no antécio inferior. Chase (1929), Hitchcock (1927) e Tovar (1993) destacaram a ocorrência alternativa da gluma inferior, o que não foi observado no material do Rio Grande do Norte. Esses autores e Macbride (1936) descreveram a ocorrência de espiguetas solitárias e pareadas sobre a ráquis. No material do Rio Grande do Norte, os pedicelos são sempre pareados, ocorrendo, em um mesmo indivíduo, ramos unilaterais com ambas as espiguetas do par desenvolvidas ou com uma abortada.

6. Paspalum fimbriatum Kunth, Nov. Gen. Sp. ed. 4, 1: 93 pl. 28. 1815 [1816]. $\quad$ Fig.1f

Plantas anuais, cespitosas, 20-44 cm alt., sem rizomas; nós glabros. Bainhas foliares delgadas, inteiras, pilosas nas porções marginais, especialmente no ápice, tricomas hialinos, sem colar de tricomas no ápice; lâminas 5-21,5 × $(0,4) 0,6-1,3 \mathrm{~cm}$, lanceoladas, não estreitadas em direção à base, planas, pilosas ou glabras em ambas as faces; lígula $0,3-0,6 \mathrm{~mm}$. Inflorescência com 1-2 ramos de 1,7-7,5 cm compr.; inflorescências axilares ausentes; ráquis $0,5-1,8 \mathrm{~mm}$ larg., com alas estreitas, estramínea, glabra; pedicelo glabro. Espiguetas pareadas, 3-4,5 × 3-4,5 mm, estramíneas, sem manchas, amplamente ovais; gluma inferior ausente; gluma superior alada, com bordos fimbriados, 3-nervada, glabra, sem cílios, membranácea; lema inferior 3-nervado, sem pálea, glabro, membranáceo, não plicado; antécio superior 2,2-3 $\times 1,5-2 \mathrm{~mm}$, amarelado, oval, liso, sem nervuras aparentes, glabro. Cariopse não disponível. Material selecionado: Pureza, $05^{\circ} 29^{\prime} 24^{\prime \prime}$ e $35^{\circ} 37^{\prime} 38^{\prime \prime} \mathrm{W}$, VII.2006, R.C. Oliveira et al. 1783 (MOSS). Serra Negra do Norte, $06^{\circ} 33^{\prime}$ '55'S e $37^{\circ} 17^{\prime} 37^{\prime}$ ' W, VII.2006, R.C. Oliveira \& C.G.T. Ferreira 1625 (MOSS).

Ocorre em todos os tipos de solo na Caatinga, aparecendo logo após as primeiras chuvas e permanecendo durante toda a estação chuvosa. Encontrada em floração e frutificação de março a novembro. Ocorre do Panamá até o Brasil (Chase 1929). No Brasil, está registrada para todo o Nordeste, Minas Gerais e Tocantins. 
Critérios regionais de ameaça segundo IUCN: LC (preocupação menor).

Distingue-se das demais espécies pelas margens fimbriadas da gluma superior, as quais conferem à espigueta e inflorescência um padrão muito distinto. Geralmente, a base da planta possui uma coloração vinácea.

7. Paspalum gardnerianum Nees, Hooker's J. Bot. Kew Gard. Misc. 2: 103. 1850.

Fig $1 \mathrm{~g}$

Plantas perenes, cespitosas, ca. $80 \mathrm{~cm}$ alt., com rizomas curtos; nós pilosos. Bainhas foliares delgadas, inteiras, as basais velutíneas, as do colmo florífero glabras, especialmente as apicais, tricomas hialinos, sem cílios marginais, sem colar de tricomas no ápice; lâminas 7,5-9,2 × 0,3-0,4 $\mathrm{cm}$, lanceoladas, não estreitadas em direção à base, planas, glabrescentes a tuberculado-pilosas em ambas as faces; lígula $0,2-0,4 \mathrm{~mm}$. Inflorescência com 3 ramos de 2,5-4 cm compr., alternos; inflorescências axilares ausentes; ráquis $0,7-1 \mathrm{~mm}$ larg., com alas estreitas, estramínea, pilosa nas margens; pedicelos com tricomas longos, dourados, com comprimento similar à espigueta. Espiguetas pareadas, 1,8-2 $\times 0,9$ $1 \mathrm{~mm}$, estramíneas quando jovens e castanho-escuras na maturidade, sem manchas, elíptico-obovais, acuminadas; gluma inferior e superior ausentes; lema inferior 2-3-nervado, sem pálea, glabro a esparsamente piloso, membranáceo, não plicado; antécio superior 1,8-2 × 0,9-1 mm, estramíneo quando jovem, castanho-escuro na maturidade, elíptico-oboval, fortemente papiloso, sem nervuras aparentes, glabro. Cariopse não disponível.

Material examinado: Ceará Mirim, VII.2006, R.C. Oliveira et al. 1759 (MOSS).

Encontrada em vegetação de Cerrado, sobre solos arenosos. Floração em julho. Ocorre desde o Panamá até o Paraguai, Brasil e Bolívia (Zuloaga $\&$ Morrone 2005). No Brasil, ocorre nas Regiões Norte, Nordeste e Centro-Oeste e Sudeste.

Critérios regionais de ameaça segundo IUCN: VU. Paspalum gardnerianum, assim como $P$. carinatum, forma subpopulações (IUCN 2003) em áreas disjuntas de Cerrado do Rio Grande do Norte, as quais ocorrem próximo ao litoral e, por isto, sofrem com o grande impacto imobiliário. Em áreas do bioma Cerrado do Brasil Central, são espécies comuns e sob critério LC (preocupação menor).

Distingue-se das demais espécies de Paspalum ocorrentes no Rio Grande do Norte pela ausência de ambas as glumas. Além disso, possui tricomas longos e dourados no ápice dos pedicelos e o lema superior fortemente papiloso.
8. Paspalum ligulare Nees, Agrostologia brasiliensis, in Mart., Fl. bras. enum. PL. 2(1): 60. 1829. Paspalum pleostachyum Döll, Fl. bras. 2(2): 58. 1877. Syn. nov.

Fig. 2

Plantas perenes, cespitosas, $15-104 \mathrm{~cm}$ alt., sem ou com rizomas muito curtos; nós glabros. Bainhas foliares delgadas, inteiras, geralmente glabras, às vezes pilosas, tricomas hialinos, ciliadas, raramente sem cílios, sem colar de tricomas no ápice; lâminas 1-64(-85) ×0,2-0,8 cm, linear ou lanceoladas, não estreitadas em direção à base, planas ou convolutas, glabras ou pilosas; lígula 3-8 mm. Inflorescências com 4-9 ramos de 2,5-19,6 $\mathrm{cm}$ compr., alternos; inflorescências axilares ausentes; ráquis 0,4-1 mm larg., áptera, ferrugínea ou estramínea, escabra nas margens; pedicelo glabro ou com tricomas hialinos mais curtos que o comprimento da espigueta. Espiguetas pareadas, 2-2,5 × 1-1,5 mm, purpúreas a estramíneas, sem manchas, elípticas, mucronuladas; gluma inferior ausente; gluma superior áptera, com bordos inteiros, 3-nervada, glabra, sem cílios, membranácea; lema inferior 3-nervado, sem pálea, glabro, membranáceo, não plicado; antécio superior 2-2,3 × 1-1,3 mm, estramíneo a ferrugíneo, elípticas ou oboval, liso, sem nervuras aparentes, glabro. Cariopse não disponível.

Material selecionado: Florânia, Fazenda São Bento, 615'S e 365'' W, VII.1981, G.F.C. Lima 225 (MOSS). Mossoró, Campus da UFERSA, 511'31"'S e 37²0'40”'W, VI2006, C.G.T.Ferreira \& R.C. Oliveira 265 (MOSS). Serra Negra do Norte, ESEC, 635'21'S e $37^{\circ} 15^{\prime} 8^{\prime \prime}$ 'W, V.2006, R.C. Oliveira \& C.G.T. Ferreira 1662 (MOSS). Tibau, praia de Areias Alvas, margem esquerda da estrada da Praia das Emanoelas em direção a Grossos, X.2005, R.C Oliveira 1606 (MOSS). Tibau do Sul, Praia da Pipa, 6²'14'S e $35^{\circ} 4^{\prime} 53^{\prime}$ 'W, 15.VII.2006, R.C. Oliveira et al. 1701 (MOSS).

Encontrada em solos arenosos a argilopedregosos ou pedregosos, em margem de estrada, na Caatinga, locais de escoamento natural de água e riachos anuais secos, em relevo plano, sendo de ocasional a comum. Prefere locais com maior saturação de água. Encontrada em floração de abril a outubro. Ocorre de Cuba até o Brasil (Renvoize 1984). No Brasil foi registrada no Pará e em quase todos os estados do nordeste, exceto no Maranhão e no Piauí.

Critérios regionais de ameaça segundo IUCN: LC (preocupação menor). Esta espécie forma populações grandes e comuns em todo o litoral do Rio Grande do Norte.

Döll (1877) relatou a afinidade entre Paspalum pleostachyum Döll e P. ligulare distinguindo-as pelo maior comprimento da lígula 


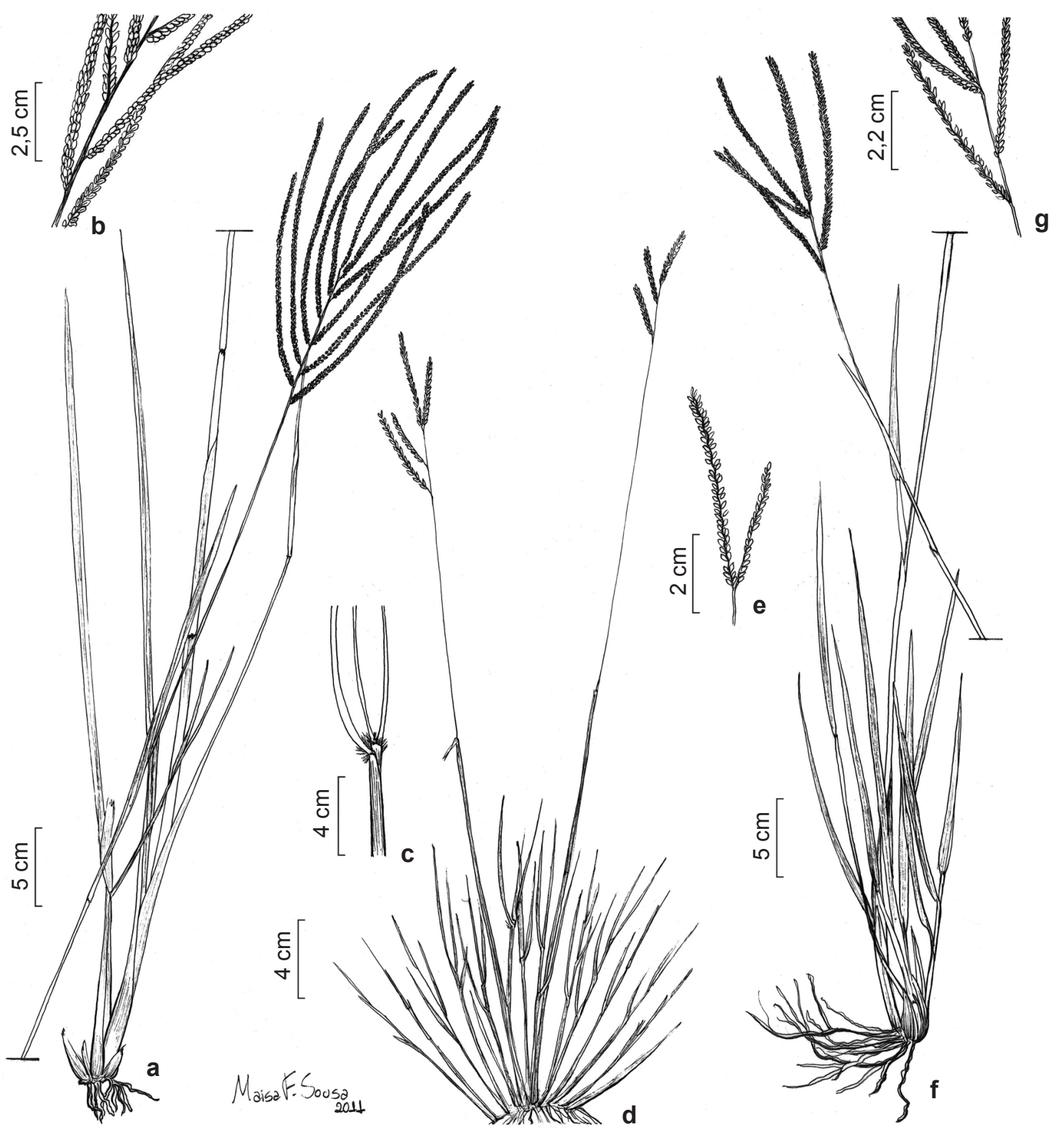

Figura 2 - a-g. Paspalum ligulare Nees - visão dos extremos morfológicos e planta intermediária; a. planta alta e de lâminas largas; b. detalhe da inflorescência; c. detalhe da região ligular; d. planta baixa e com lâminas estreitas; e. detalhe da inflorescência; f. planta de porte médio; g. detalhe da inflorescência. (a-c Oliveira et al. 1662; d-e Oliveira et al. 1701; f-g Oliveira et al. 1606). Figure 2 - a-g. Paspalum ligulare Nees - showing both the morphological extremes and intermediate; a. habit of tall plant with wide leaf blades; b. detail of the inflorescence; c. detail of ligular region; d. habit of short plant with narrow leaf blades; e. detail of the inflorescence; f. habit of medium sized plant; g. detail of the inflorescence. (a-c Oliveira et al. 1662; d-e Oliveira et al. 1701; f-g Oliveira et al. 1606).

e da espigueta de P. pleostachyum. Renvoize (1984) agregou caracteres para diferenciá-las como o hábito mais robusto e as lâminas foliares mais largas de P. pleostachyum.

Os extremos morfológicos observados por Döll (1877) e Renvoize (1984) são conectados por intermediários que mostram sobreposição entre os estados de caráter. Há intermediários entre indivíduos de uma mesma população e a variação no tamanho da planta também é influenciada pelo pastejo, já que essa espécie é apetecida por caprinos, segundo observação de campo. A presente proposta de sinonimização foi estruturada pela observação intensa das populações no campo, de indivíduos 
cultivados em vasos, provenientes de diversas localidades do nordeste (mantidos em telado na Embrapa Recursos Genéticos e Biotecnologia) e de material de herbário. A Figura 2 mostra extremos morfológicos com um elemento intermediário.

\section{Paspalum loefgrenii Ekman, Ark. Bot. 10(17):} 15. 1911.

Fig. 3a

Plantas anuais, cespitosas, ca. $95 \mathrm{~cm}$ alt., com rizomas; nós pilosos. Bainhas foliares delgadas, fibrosas, pilosas, tricomas dourados, sem cílios, formando um colar de tricomas no ápice; lâminas 24,5-32,5 × 1-1,4 cm, lanceoladas, não estreitadas em direção à base, planas, glabras em ambas as faces; lígula ca. $8 \mathrm{~mm}$. Inflorescências com 9 ramos de 4-11 cm de compr., alternos; inflorescências axilares ausentes; ráquis ca. $1 \mathrm{~mm}$ larg., áptera, estramínea, glabra; pedicelo glabro. Espiguetas pareadas, 2,8-3× $1,5 \mathrm{~mm}$, estramíneas, sem manchas, obovais, agudas; gluma inferior ausente; gluma superior áptera, com bordos inteiros, 5-nervada, pilosa no dorso, tricomas não visíveis a olho nu, sem tricomas clavados no ápice, sem cílios, membranácea; lema inferior 3-nervado, sem pálea, piloso, tricomas não clavados, membranáceo, não plicado; antécio superior 2,8-3 $\times 1,5 \mathrm{~mm}$, estramíneo, oboval, liso, com 3 nervuras aparentes, piloso. Cariopse não disponível.

Material examinado: Coronel João Pessoa, localidade Mata Redonda, $6^{\circ} 16^{\prime}$ 'S e $38^{\circ} 23^{\prime} \mathrm{W}, \mathrm{V} .1981$, O.F. de Oliveira et al. 1827 (MOSS).

Coletada em solos areno-argilosos e pedregosos, tem larga e frequente distribuição. Encontrada em floração em maio. Ocorre na Venezuela, Guiana (Judziewicz 1990) e Brasil, onde possui registros para as Regiões Norte, Nordeste e Centro-oeste.

Critérios regionais de ameaça segundo IUCN: DD. A descrição de $P$. loefgrenii aqui apresentada foi baseada em um único espécime e a população não foi relocalizada, porém, não houve esforço de coleta suficiente para avaliar o grau de ameaça regional da espécie.

10. Paspalum maritimum Trin., Mém. Acad. Imp. Sci. Saint-Petersbourg, Sér. 6, Sci. Math., Second Pt. Sci. Nat. 1: 148. 1834.

Fig. 3b

Plantas perenes, estoloníferas, $50-100 \mathrm{~cm}$ alt., com rizomas; nós glabros ou esparsamente pilosos, estolhos podendo alcançar vários metros de comprimento. Bainhas foliares delgadas, inteiras, glabras, pilosas ou tuberculado-pilosas, especialmente próximo às margens, tricomas hialinos, sem cílios marginais, sem colar de tricomas no ápice; lâminas 4-29 × 0,5-1 cm, lanceoladas, não estreitadas em direção à base, planas, glabras ou pilosas na face abaxial, face adaxial geralmente glabra, às vezes pilosas ou tuberculado-pilosas em ambas as faces; lígula 5-8 mm. Inflorescência com 1-5 ramos de 3-9 cm compr., alternos; inflorescências axilares presentes; ráquis em torno de $0,8 \mathrm{~mm}$ larg., áptera, esverdeada, com tricomas mais curtos que o comprimento da espigueta; pedicelo glabro. Espiguetas pareadas, 1,6-2,1 × 1-1,1 mm, amareladas a castanho-escuras, sem manchas, obovais, agudas; gluma inferior ausente; gluma superior áptera, com bordos inteiros, 3-nervada, levemente tuberculado-estrigosa, tricomas não visíveis a olho nu, sem tricomas clavados no ápice, sem cílios, membranácea; lema inferior 3-nervado, sem pálea, glabro, membranáceo, não plicado; antécio superior 2,1 $\times 1-1,1 \mathrm{~mm}$, estramíneo, oboval, liso, sem nervuras aparentes, glabro. Cariopse não disponível.

Material selecionado: Mossoró, Campus da UFERSA, $5^{\circ} 11^{\prime} 31^{\prime \prime}$ 'S e $37^{\circ} 20^{\prime} 40^{\prime \prime} \mathrm{W}, \mathrm{VI} .1981$, O.F. de Oliveira 871 (MOSS). Natal, Campus da UFRN, Setor II, 5'53'S e $35^{\circ} 10^{\prime}$ W, III.1993, I.X. Carvalho (MOSS 3810). Nísia Floresta, Lagoa do Bonfim, margem da estrada, $6^{\circ} 1$ ' $58^{\prime \prime} \mathrm{S}$ e $35^{\circ} 12^{\prime} 55^{\prime}$ 'W, 14.VII.2006, R.C. Oliveira et al. 1678 (MOSS).

Espécie abundante, formando densas populações. Encontrada em solos arenosos ou humíferos, dunas, campos antropizados, florestas subperenifólias e perturbadas, em relevo plano a levemente ondulado. Encontrada em floração de março a agosto. Ocorre nas Antilhas (Cuba), Colômbia e Brasil (Judziewicz 1990) ao longo da costa atlântica, até o sul do Brasil.

Critérios regionais de ameaça segundo IUCN: LC (preocupção menor).

Espécie caracterizada pelos rizomas e estolhos muito longos. A ocorrência de estolhos foi omitida nos trabalhos de Oliveira \& Valls (2001) e Maciel et al. (2009a), a despeito do fato de os estolhos poderem atingir vários metros de comprimento em áreas de vegetação rala. Porém, em gramados densos, tendem a ser mais reduzidos. Os rizomas, que também ocorrem, são bem diferenciados pela presença dos catafilos (ver Fig. 3b).

11. Paspalum melanospermum Desv. ex Poir., Encycl., Suppl. 4: 315. $1816 . \quad$ Fig. 3c

Plantas anuais, cespitosas, $29-68 \mathrm{~cm}$ alt., sem rizomas; nós glabros. Bainhas foliares delgadas, inteiras, glabras no dorso, com tricomas longos nas margens, tricomas hialinos, sem cílios, sem colar de tricomas no ápice; lâminas 5,5-28,5 × 0,3-1 $\mathrm{cm}$, lanceoladas, não estreitadas em direção à base, 


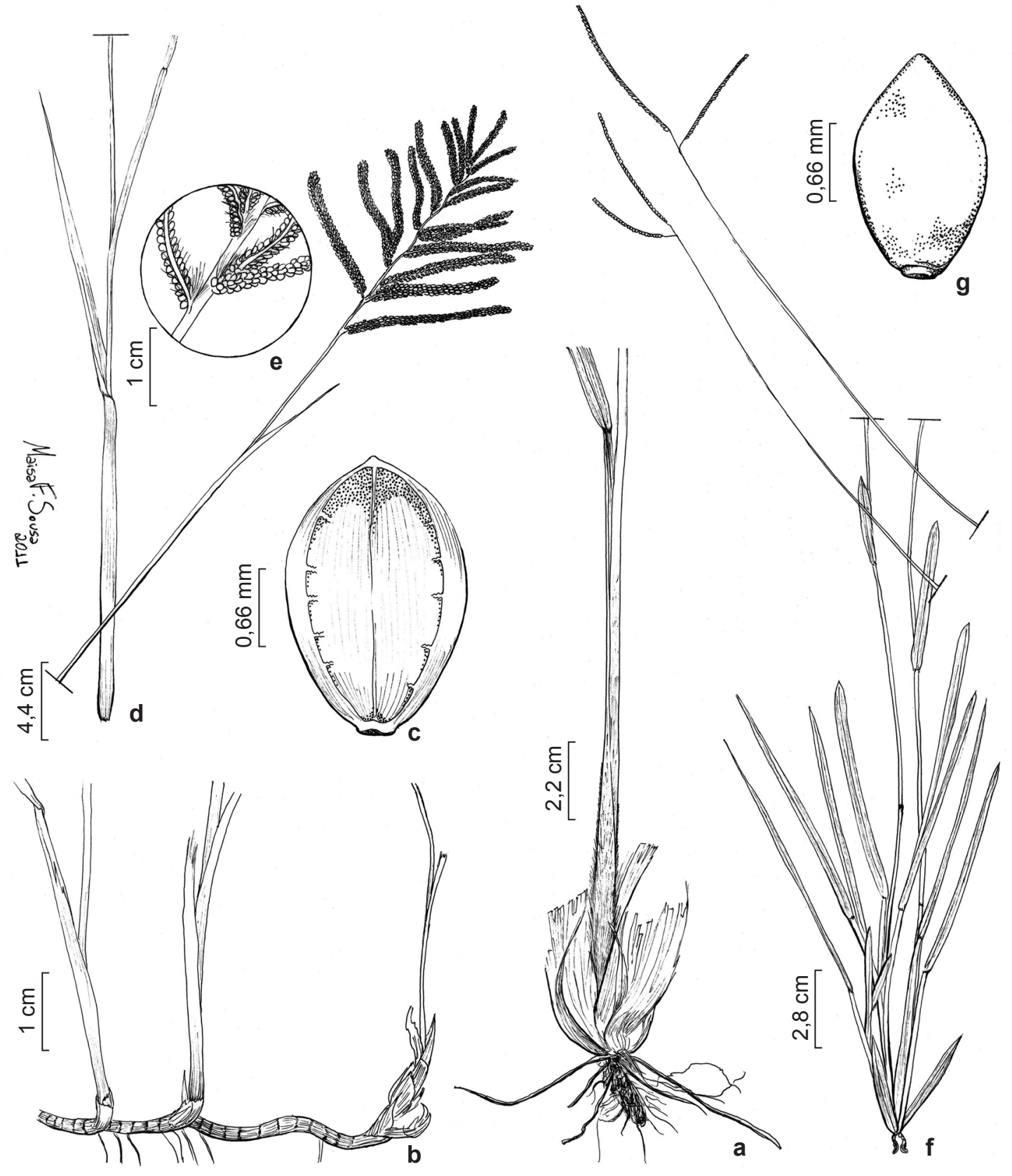

Figura 3 - a. Paspalum loefgrenii Ekman - base da planta mostrando pilosidade e rizoma. b. Paspalum maritimum Trin. - rizoma. c. Paspalum melanospermum Desv. ex Poir. - vista do lema inferior plicado. d-e. Paspalum millegrana Schrad. - d. folhas e inflorescência; e. ráquis mostrando tricomas longos nas margens. f-g. Paspalum pumilum Nees - f. ramo mostrando forma das lâminas e inflorescência com ramos terminais e subconjugados; g. espigueta, vista dorsal. (a Oliveira et al. 1827; b. Carvalho MOSS-3810; c Oliveira et al. 1915 ; d-e Oliveira et al. 2035; f-g Oliveira et al. 2000).

Figure 3 - a. Paspalum loefgrenii Ekman - base of the plant showing indumentum and rhizome. b. Paspalum maritimum Trin. rhizome; c. Paspaum melanospermum Desv. ex Poir. - view of the plicate lower lemma. d-e. Paspalum millegrana Schrad. - d. leaves and inflorescence; e. rachis showing the long trichomes on the margins. f-g. Paspalum pumilum Nees - f. branch showing lamina form and inflorescence with terminal and subconjugate branches; g. spikelet, dorsal view. (a Oliveira et al. 1827; b Carvalho MOSS-3810; c Oliveira et al. 1915 ; d-e Oliveira et al. 2035; f-g Oliveira et al. 2000). 
planas, face abaxial glabra e face adaxial glabra ou pilosa, com tricomas marginais esparsos; lígula 2-7 mm. Inflorescências com 4-5 ramos de 3,5-7 $\mathrm{cm}$ compr.; inflorescências axilares ausentes, ráquis 0,5-1,5 mm larg., áptera, esverdeada, tricomas na base; pedicelo glabro ou com tricomas hialinos mais curtos que o comprimento da espigueta. Espiguetas pareadas, 2-2,2 × 1,5-2 mm, castanhoescuras ou atro-purpúreas, sem manchas, obovadoarredondadas, mucronuladas; gluma inferior ausente; gluma superior áptera, com bordos inteiros, 5-nervada, pilosas ou glabras, tricomas não visíveis a olho nu, sem tricomas clavados no ápice, sem cílios, membranácea, conspícuamente plicada; lema inferior 5-nervado, sem pálea, piloso ou glabro, membranáceo, não plicado; antécio superior 2-2,2 $\times 1,5-2 \mathrm{~mm}$, castanho-escuro ou atro-purpúreo, oboval, liso, sem nervuras aparentes, glabro. Cariopse não disponível.

Material selecionado: Jardim de Piranhas, Fazenda Sobrado, 627'30"'S e 3705'52'W, IV.1981, G.F.C Lima 157 (MOSS). Serra Negra do Norte, ESEC, IV.2007, R.C. Oliveira et al. 1915 (MOSS).

Coletada no alto da serra e em Caatinga arbórea aberta, em solos de aluvião e arenosos. Encontrada em floração em abril. Ocorre no Panamá, Antilhas até Colômbia, Venezuela, Guianas e Brasil (Judziewicz 1990), onde é encontrada em quase todo o país.

Critérios regionais de ameaça segundo IUCN: LC (preocupação menor).

Caracteriza-se pelas pequenas espiguetas oboval-arredondadas, antécio atro-púrpureo e lema inferior plicado.

12. Paspalum millegrana Schrad. in Schult., Mant. 2: 175.1824.

Fig. 3d-e

Plantas perenes, cespitosas, ca. $115 \mathrm{~cm}$ alt., sem rizomas; nós glabros. Bainhas foliares delgadas, inteiras, geralmente glabras ou com tricomas no ápice, tricomas hialinos, sem cílios, sem colar de tricomas no ápice; lâminas $16,4-55,5 \times 0,8-0,9 \mathrm{~cm}$, linear-lanceoladas, não estreitadas em direção à base, planas, tuberculado-pubescentes a quase glabras em ambas as faces; lígula 2,1-3,6 mm. Inflorescência com (4-)16-40 ramos de 3,5-9,2 cm compr., alternos; inflorescências axilares ausentes; ráquis ca. $1 \mathrm{~mm}$ larg., áptera, esverdeada, com tricomas longos e esparsos nas margens; pedicelo estrigoso nas margens, mais curtos que o comprimento da espigueta, hialinos. Espiguetas pareadas, $2,1-2,2 \times 1,5-1,9 \mathrm{~mm}$, estramíneas a vináceas, sem manchas, orbiculares ou amplamente obovais, levemente apiculadas; gluma inferior ausente; gluma superior áptera, com bordos inteiros, 3-nervada, glabra, sem cílios, membranácea; lema inferior 3-nervado, sem pálea, glabro, membranáceo, não plicado; antécio superior 2,1-2,2 × 1,5-1,9 $\mathrm{mm}$, pálido-amarelado, suborbicular, papiloso, sem nervuras aparentes, glabro. Cariopse 1,3-1,5 × 1,1-1,8 $\mathrm{mm}$, fortemente oboval.

Material selecionado: Baía Formosa, $3 \mathrm{~km}$ após a Praia do Sagi, Próximo à estação eólica, 6²7'30"S e 3458'41”'W, XI.2007, R.C. Oliveira et al. 2035 (MOSS). Pureza, Distrito de Tabaiana, a $9 \mathrm{~km}$ de Pureza, margem da estrada, $5^{\circ} 29^{\prime} 24^{\prime \prime}$ 'S e $35^{\circ} 37^{\prime} 38^{\prime \prime} \mathrm{W}$, VII.2006, R.C. Oliveira et al. 1782 (MOSS).

Critérios regionais de ameaça segundo IUCN: LC (preocupação menor)

Coletada em ambiente de Cerrado antropizado, locais úmidos em Caatinga Hiperxerófila, margens de estradas, em solos arenosos e argilosos de relevo ondulado a plano. Encontrada em floração de fevereiro a novembro e em frutificação em abril. Ocorre das Antilhas e América Central (Chase 1929) até o Brasil, nas Regiões Norte, Nordeste e Sudeste.

Caracterizada pelo porte robusto de suas touceiras, inflorescência com aspecto piramidal, espigueta orbicular-obtusas com 2,1-2,2 $\mathrm{mm}$ de comprimento e gluma superior cartilaginosa.

13. Paspalum pumilum Nees, Agrostologia brasiliensis, in Mart., Fl. bras. enum. Pl. 2: 52. 1829.

Fig. 3f-g

Plantas perenes, formando touceiras achatadas e circulares, ca. $50 \mathrm{~cm}$ alt., com rizomas curtos; nós glabros. Bainhas foliares delgadas, inteiras, pilosas, tricomas hialinos, sem cílios, sem colar de tricomas no ápice; lâminas 10-12 × 0,5 cm, linear-lanceoladas, base levemente mais estreita, planas, densamente pubescentes em ambas as faces; lígula 0,6 mm. Inflorescência com 2 ramos de 4-6,5 cm compr., subconjugados; inflorescências axilares ausentes; ráquis ca. 0,6 mm larg., áptera, esverdeada, glabra; pedicelo glabro. Espiguetas solitárias, $2 \times 1,4 \mathrm{~mm}$, estramíneas, sem manchas, ovais, agudas; gluma inferior ausente; gluma superior áptera, com bordos inteiros, 4-nervada, glabra, sem cílios, membranácea; lema inferior 3-nervado, sem pálea, glabro, membranáceo, não plicado; antécio superior 1,6-1,9 × 1,2-1,4 mm, estramíneo, oval, obtuso, levemente papiloso, sem nervuras aparentes, glabro. Cariopse não disponível. Material examinado: Baía Formosa, Praia do Sagi, entrada da vila, $6^{\circ} 27^{\prime} 54^{\prime \prime}$ 'S e $34^{\circ} 58^{\prime} 47^{\prime \prime} \mathrm{W}$, IX.2007, R.C. Oliveira et al. 2000 (MOSS).

Coletada em campo úmido, na margem de riacho, formando uma pequena mancha, com sinais de pastejo, ocasional. Encontrada em floração em novembro. América Central e Antilhas, até 
noroeste da Argentina e Uruguai (Zuloaga \& Morrone 2005). No Brasil, em quase todo o País (Valls \& Oliveira 2012).

Critérios regionais de ameaça segundo IUCN: VU. Embora seja uma espécie de ampla distribuição, no Rio Grande do Norte é encontrada apenas na região de Floresta Atlântica do litoral leste do Estado, insuficientemente protegida por unidades de conservação.

O espécime do Rio Grande do Norte apresentou espiguetas com $2 \mathrm{~mm}$ de comprimento, extrapolando o limite de $1,8 \mathrm{~mm}$ mencionado por Zuloaga et al. (2004) e Zuloaga \& Morrone (2005) para distingui-la de Paspalum minus E. Fourn. Para Canto-Dorow et al. (1996), e na circunscrição adotada no presente trabalho, o limite morfológico de $P$. pumilum é mais amplo, com espiguetas atingindo $2,5 \mathrm{~mm}$ de comprimento. Paspalum minus E. Fourn. possui espiguetas ainda mais longas e lâminas foliares lineares.

14. Paspalum repens Berg., Acta Helv. Phys.Math. 7: 129. $1762 . \quad$ Fig. 4a-b

Plantas perenes, decumbentes, $200 \mathrm{~cm}$ alt., rizomas longos; nós pubescentes. Bainhas foliares infladas, inteiras, pubescentes, tricomas hialinos, sem cílios marginais, com colar de tricomas no ápice; lâminas 10-25 × 0,6-1,5 cm, lanceoladas, não estreitadas em direção à base, planas, pubescentes; lígula 1,5-3 mm. Inflorescência com 20-50 ramos de 2,5-10 cm compr., alternos; inflorescências axilares ausentes; ráquis 1-1,5 mm larg., alada, glabra; pedicelo glabro. Espiguetas solitárias, 1,9-2,4 $\times$ 0,9-0,3 mm, estramíneas, sem manchas, elípticas, acuminadas; gluma inferior ausente; gluma superior áptera, com bordos inteiros, 2-nervada, glabra, membranácea; lema inferior 2-nervado, sem pálea, glabro, membranáceo, não plicado; antécio superior 1,7-1,8 × 0,9-1 mm, estramíneo, elíptico, liso, sem nervuras aparentes, glabro. Cariopse não disponível. Material examinado: Tenente Ananias, 06 27'54'S e 38¹0'48”'W, Fazenda São Braz de Cima, 18.VI.1986, Sarmento 803 (RB).

Espécie aquática flutuante, coletada em lagoas na Caatinga. Encontrada em floração ao longo de todo o ano. Ocorre desde os EUA até a Argentina e o Uruguai, sendo encontrada nas ilhas do Caribe (Zuloaga \& Morrone 2005). No Brasil ocorre em praticamente todo o País.

Critérios regionais de ameaça segundo IUCN: DD. Foi analisada apenas uma exsicata da espécie, citada anteriormente para o Rio Grande do Norte (Morrone et al. 1996). Em algumas regiões do
Brasil, Paspalum repens é considerada invasora de ambientes aquáticos (Lorenzi 2000, Carbonari et al. 2004). No Rio Grande do Norte não foi observada a campo durante o presente trabalho e tampouco foi registrada por Henry-Silva et al. (2010), que trataram das espécies aquáticas de um rio do Rio Grande do Norte.

Espécie de fácil identificação por ser aquática e por suas bainhas infladas. Possui uma ampla variação de altura, podendo atingir até $2 \mathrm{~m}$. Também se caracteriza pela ráquis alada que se prolonga além da última espigueta.

15. Paspalum scutatum Nees ex Trin., Gram. Panic. 105. 1826.

Fig. 4c

Plantas anuais, cespitosas, 12-62 cm alt., sem rizomas; nós glabros. Bainhas foliares delgadas, inteiras, pilosas próximo à lígula, com tricomas alvos, sem cílios, sem colar de tricomas no ápice; lâminas 2-7,5 ×0,4-0,8 cm, lanceoladas, levemente estreitadas na base, planas, densamente pilosas em ambas as faces; lígula 2-4 mm. Inflorescências com 2-5 ramos de 1-6 cm compr., alternos; inflorescências axilares presentes; ráquis $0,3-0,8$ mm larg., áptera, estramínea a castanhas, pilosas na base; pedicelo glabro. Espiguetas solitárias, 1,5-2,5 $\times 1,2-2 \mathrm{~mm}$, estramíneas a purpúreas, sem manchas, escutiformes, agudas; gluma inferior ausente; gluma superior áptera, com bordos inteiros, 5-nervada, glabra, coriácea; lema inferior 2-nervado, sem pálea, glabro, membranáceo, não plicado; antécio superior 1,5-2,7 × 1,1-1,6 mm, estramíneo a purpúreo, largo-oboval, liso, sem nervuras aparentes, glabro. Cariopse 1-1,2 × 0,6-1,2 mm, oboval.

Material selecionado: Jandaíra, Estação Ecológica de Terras Secas, 5'21'23'S e 377'41'W, V.1986, S.H. Vasconcelos 38 (MOSS). Natal, Dunas Costeiras, setor B, 5\%48'S e 3513'W, IX.1980, Projeto Parque das Dunas 110 (MOSS). Serra Negra do Norte, ESEC, 6³4'28'S e 37¹6'01'W, VI.2006, C.G.T. Ferreira \& G.S. Araújo 229 (MOSS).

Coletada em Dunas Costeiras, Caatinga hiperxerófila densa, Caatinga aberta e em lajedo. Solos arenosos a pedregosos, relevo ondulado. Encontrada em floração e frutificação de maio a junho. Espécie endêmica da Caatinga (Maciel et al. 2009b).

Critérios regionais de ameaça segundo IUCN: LC (preocupação menor).

Reconhecida pelas espiguetas em forma de escudo. Espécie anual muito comum na Caatinga, tem seu ciclo de vida associado ao período chuvoso. Surge após iniciadas as chuvas e permanece por um período após a fase inicial da estiagem, quando finaliza a dispersão dos seus diásporos. 


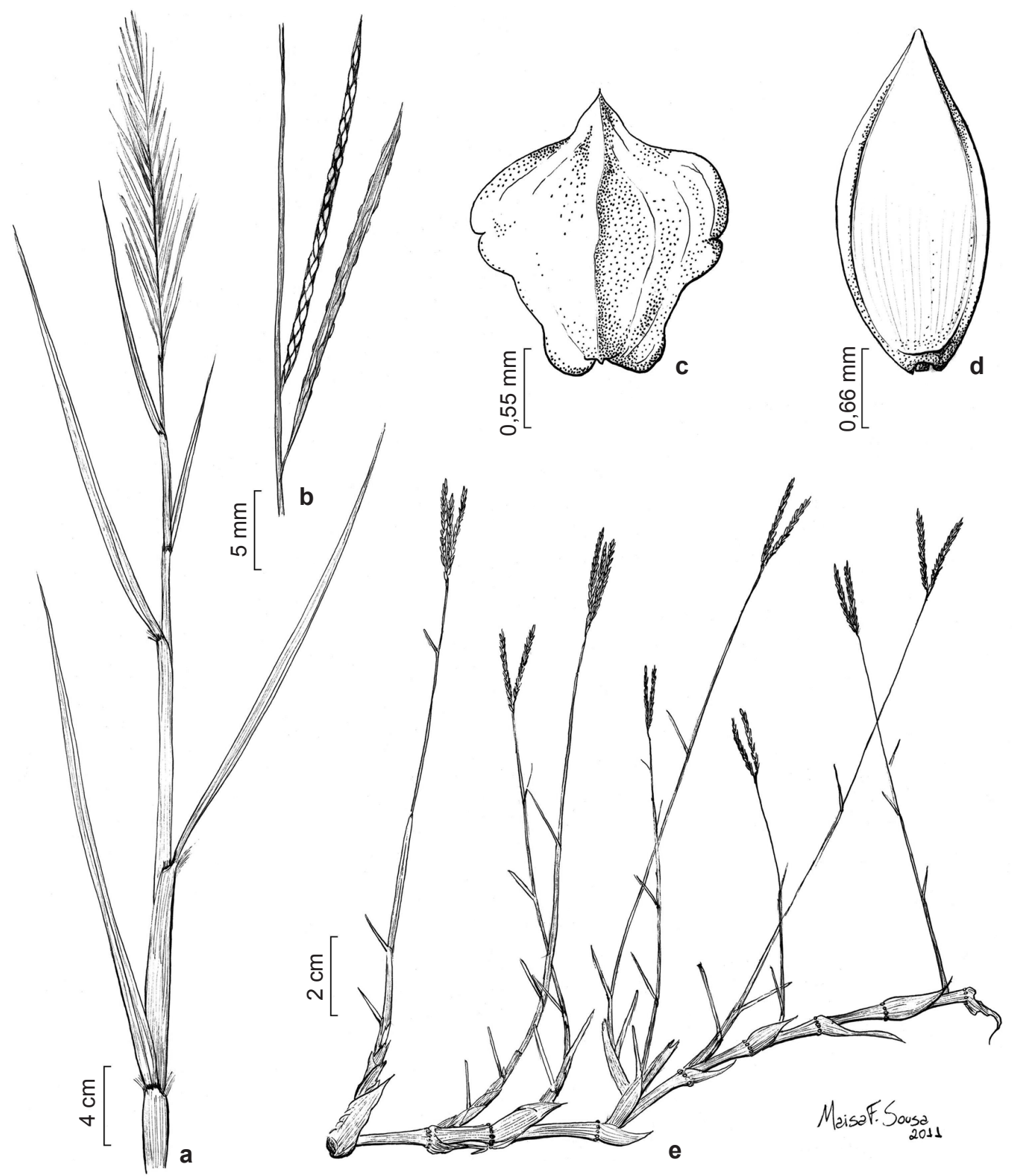

Figura 4 - a-b. Paspalum repens P.J. Bergius - a. parte do colmo florífero; b. detalhe da ráquis alada. c. Paspalum scutatum Nees ex Trin. - espigueta, vista dorsal. d-e. Paspalum vaginatum Sw. - d. espigueta, vista ventral; e. hábito. (a-b Paula 3007; c Ferreira \& Araújo 229; d-e Ribeiro 29).

Figure 4 - a-b. Paspalum repens P.J. Bergius - a. part of flowering culm; b. detail of winged rachis. c. Paspalum scutatum Nees ex Trin. - spikelet, dorsal view. d-e. Paspalum vaginatum Sw. - d. spikelet, ventral view; e. habit. (a-b Paula 3007; c Ferreira \& Araújo 229; d-e Ribeiro 29).

16. Paspalum vaginatum Sw., Prodr.: 21. 1788.

Fig. 4d-e

Plantas perenes, estoloníferas, $8,5-30 \mathrm{~cm}$ alt., sem rizomas; nós glabros. Bainhas foliares delgadas, inteiras, glabras ou com tricomas próximo às margens, em especial na porção apical, tricomas hialinos, sem cílios, sem colar de tricomas no ápice; lâminas 1-7 ×0,3-0,4 cm, linear-lanceoladas ou lanceoladas, não estreitadas em direção à base, convolutas, subconvolutas ou raramente planas, glabras ou com tricomas esparsos em ambas as faces; lígula 1-1,5 $\mathrm{mm}$. Inflorescência com 
2-3 ramos de 3-12 cm compr., conjugados ou subconjugados; inflorescências axilares ausentes; ráquis $0,6-0,8 \mathrm{~mm}$ larg., com asas estreitas, esverdeadas, glabra; pedicelo glabro ou piloso com tricomas mais curtos que o comprimento da espigueta, hialinos. Espiguetas solitárias, 2,7-3 × 1,1-1,5 mm, alvas, esverdeadas ou estramíneas, sem manchas, elíptico-ovais, agudas; gluma inferior ausente, raramente presente em algumas espiguetas, então diminutas; gluma superior áptera, com bordos inteiros, 3-5-nervada, pilosa, tricomas não visíveis a olho nu, tricomas não clavados, com cílios, membranácea; lema inferior 5-nervado, sem pálea, glabro, membranáceo, não plicado; antécio superior 2-2,6 × 1,1-1,2 mm, estramíneo, elíptico-oval, liso, sem nervuras aparentes, com um tufo de tricomas no ápice ou glabro. Cariopse não disponível.

Material selecionado: Baía Formosa, próximo à Barra do Sagi, 6028'00"S e $34^{\circ} 58^{\prime} 40^{\prime}$ "W, XI.2007, A.R.O. Ribeiro et al. 29 (MOSS). Mossoró, margem do Rio

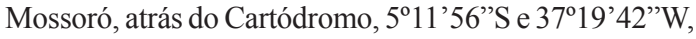
XII.2002, A.R.O. Ribeiro 92 (MOSS). Tibau, Praia das Emanoelas, na estrada para Areias Alvas, XII.2006, R.C. Oliveira et al. 1830 (MOSS).

Coletada em margem antropizada de rio, dunas litorâneas nativas ou antropizadas, em solos arenosos e argilosos com relevo de ondulado a plano. Encontrada em floração de julho a novembro e em frutificação em setembro. Pantropical, na América ocorre desde o sudeste dos Estados Unidos, Caribe, Chile até a Argentina e Uruguai (Zuloaga \& Morrone 2005). No Brasil, distribui-se em todos os estados.

Critérios regionais de ameaça segundo IUCN: LC (preocupação menor).

Caracterizada pelos estolhos longos e folhas distribuídas disticamente ao longo do colmo florífero ereto. As espiguetas solitárias, com cílios e elíptico-ovais de ca. $3 \mathrm{~mm}$ de comprimento auxiliam na identificação desta espécie.

\section{Agradecimentos}

Agradecemos ao coletor e colega Odaci Fernandes, a parceria em expedições e, principalmente, o estímulo ao estudo da Flora do Rio Grande do Norte; à Kátia Pinheiro, o brilhante e estimulante trabalho no herbário MOSS, bem como aos revisores a paciente revisão do manuscrito.

\section{Referências}

Barreto, I.L. 1974. O gênero Paspalum (Gramineae) no Rio Grande do Sul. Tese de Livre Docência. Universidade Federal do Rio Grande do Sul, Porto Alegre. 258p.
Canto-Dorow, T.S.; Longhi-Wagner, H.M. \& Valls, J.F.M. 1996. Revisão taxonômica das espécies de Paspalum L., grupo Notata (Poaceae-Paniceae) do Rio Grande do Sul, Brasil. Iheringia 47: 3-44.

Carbonari, C.A.; Martins, D.; Terra, M.A. \& Marchi, S.R. 2004. Controle químico de Panicum repens e Paspalum repens. Planta Daninha 22: 453-460.

Chase, A. 1929. The North American species of Paspalum. Contributions from the United States National Herbarium 28: 1-310.

Denham, S.S. 2005. Revisión sistemática del subgénero Harpostachys de Paspalum (Poaceae: Panicoideae: Paniceae). Annals of the Missouri Botanical Garden 92: 463-532.

Denham, S.S.; Zuloaga, F.O. \& Morrone, O. 2002. Systematic revision and phylogeny of Paspalum subgenus Ceresia (Poaceae: Panicoideae: Paniceae). Annals of the Missouri Botanical Garden 89: 337-399.

Denham, S.S. \& Zuloaga, F.O. 2007. Phylogenetic relationships of the Decumbentes group of Paspalum, Thrasya, and Thrasyopsis (Poaceae: Panicoideae: Paniceae). Aliso 23: 545-562.

Döll, J.C. 1871-1877. Gramineae I. In: Martius, C.F.P. von \& Eichler, A.W. (eds.). Flora brasiliensis. Vol. 2, pt. 2. Pp. 1-357.

Ducke, A. 1959. Estudos botânicos no Ceará. Anais da Academia Brasileira de Ciências 31: 211-308.

Ferreira, C.G.T.; Oliveira, R.C.; Valls, J.F.M. \& Loiola, M.I.B. 2009. A família Poaceae na Estação Ecológica do Seridó, RN. Hoehnea 36: 679-707.

Filgueiras, T.S.; Longhi-Wagner, H.M.; Viana, P.L.; Zanin, A.; Guglieri, A.; Oliveira, R.C.; Canto- Dorow, T.S.; Shirasuna, R.T.; Valls, J.F.M.; Oliveira, R.P.; Rodrigues, R.S.; Santos-Gonçalves, A.P. \&Welker, C.A.D. 2013. Poaceae. In: Lista de espécies da flora do Brasil. Jardim Botânico do Rio de Janeiro. Available in $<\mathrm{http}: / / \mathrm{http}$ ://floradobrasil.jbrj.gov.br $>$. Access on 18 Mar 2013.

GPWG - Grass Phylogeny Working Group. 2001. Phylogeny and subfamilial classification of the grasses (Poaceae). Annals of the Missouri Botanical Garden 88: 373-457.

Henry-Silva, G.G.; Moura, R.S.T. \& Dantas, L.L.O. 2010. Richness and distribution of aquatic macrophytes in Brazilian semi-arid aquatic ecosystems. Acta Limnologica Brasiliensia 22: 147-156.

Hitchcock, A.S. 1927. The grasses of Ecuador, Perú and Bolivia. Contributions from United States National Herbarium 24: 291-256.

Hokche, O.; Berry, P.E. \& Huber, O. 2008. Nuevo catalogo de la flora vascular de Venezuela. Fundación Instituto Botánico de Venezuela, Caracas. 860p.

Hojsgaard, D.; Schegg, E.; Valls, J.F.M.; Martínez, E.J. \& Quarín, C.L. 2008. Sexuality, apomixis, ploidy levels, and genomic relationships among four Paspalum species of the subgenus Anachyris. Flora 203: 535-547. 
IUCN. 2003. Guidelines for application of IUCN Red List criteria at regional levels: Version 3.0. Disponível em <http://intranet.iucn.org/webfiles/doc/SSC/ SSCwebsite/Red_List/regionalguidelinesSP.pdf $>$. Acesso em 8 Out 2012.

Judziewicz, E. 1990. Family 187. Poaceae (Gramineae). In: A.R,A. Görts-van Rijn (ed.). Fl. Guianas, ser. A, Phanerog. Koeltz Scientific Books, Königstein. Vol. 8. Pp. 1-727

Longhi-Wagner, H.M. 2012. Poaceae: an overview with reference to Brazil. Rodriguésia 63: 89-100.

Longhi-Wagner, H.M.; Bittrich, V.; Wanderley, M.G.L. \& Shepherd, J.G. 2001. Poaceae. In: Wanderley, M.G.L.; Shepherd, G.J. \& Giulietti, A.M. (eds.). Flora fanerogâmica do estado de São Paulo. Vol. 1. Hucitec, São Paulo. Pp. 1-292.

Lorenzi, H. 2000. Plantas daninhas do Brasil: terrestres aquáticas, parasitas, tóxicas e medicinais. $3^{\mathrm{a}} \mathrm{ed}$. Plantarum, Nova Odessa. 440p.

Macbride, J.F. 1936. Paspalum. In: Flora of Peru. Part I. Field Museum of Natural History 351: 96-261.

Maciel, J.R; Oliveira, R.C. \& Alves, M. 2009a. Paspalum L. (Poaceae: Panicoideae: Paniceae) no estado de Pernambuco, Brasil. Acta Botanica Brasilica 23: 1145-1161.

Maciel, J.R.; Alves, M. \& Oliveira, R.C. 2009b. Padrões de distribuição das espécies de Paspalum L. (Poaceae: Panicoideae: Paniceae) ocorrentes em Pernambuco, Brasil. Revista Brasileira de Botanica 32: 597-605.

Maciel, J.R. \& Alves, M. 2011. A família Poaceae na Serra de Itabaiana, Parque Nacional Serra de Itabaiana, Sergipe-Brasil. Caatinga 24: 85-93.

Morrone, O; Vega, A.S. \& Zuloaga, F.O. 1996. Revisión de las especies del género Paspalum L. (Poaceae: Panicoideae: Paniceae), grupo Dissecta (s. str.). Candollea 51: 103-138.

Oliveira, R.C. \& Valls, J.F.M. 2001. Paspalum L. In: Longhi-Wagner, H.M.; Bittrich, V.; Wanderley, M.G.L. \& Shepherd, G.J. (eds.). Poaceae. Flora fanerogâmica do estado de São Paulo. Vol. 1. Hucitec, São Paulo. Pp. 191-228.

Oliveira, R.C. \& Valls, J.F.M. 2008. Novos sinônimos e ocorrências em Paspalum (Poaceae). Hoehnea 35: 125-131.

Paiva, M.P. 2003. Os naturalistas e o Ceará: IX - Phillip Von Luetzelburg (1880-1948). Revista do Instituto do Ceará 117: 41-53.
Radford, A.E. 1986. Fundamentals of plant systematics. Harper \& Row, New York. 512p.

Renvoize, S.A. 1984. The grasses of Bahia. Royal Botanic Gardens, Kew. 300p.

Silva, T.S.; Burman, AG. \& Sendulsky, T. 1979. Espécies de Paspalum da Ilha do Cardoso, estado de São Paulo. Hoehnea 8: 11-28.

Soreng, R.J.; Davidse, G.; Peterson, P.M.; Zuloaga, F.O.; Judziewicz, E.J.; Filgueiras, T.S. \& Morrone, O. 2003 and onwards. On-line taxonomic novelties and updates, distributional additions and corrections, and editorial changes since the four published volumes of the Catalogue of New World grasses (Poaceae) published in Contributions United States National Herbarium vols. 39, 41, 46, e 48. Disponível em <http://www.tropicos.org/Project/ CNWG $>$. Acesso em 10 Mar 2011.

Swallen, J.R. 1934. Collecting grasses in Norheastern Brazil. Exploration and Field-Work of the Smithsonian Institution: 37-40.

Swallen, J.R. 1967. New species of Paspalum. Phytologia 14: 358-389.

Thiers, B. [continuamente atualizado]. Index Herbariorum: a global directory of public herbaria and associated staff. New York Botanical Garden's Virtual Herbarium. Disponível em <http:// sweetgum. nybg.org/ih/>. Acesso em 15 Mar 2013.

Tovar, O. 1993. Las Gramíneas (Poaceae) del Perú. Ruizia 13: 1-480.

Valls, J.F.M. \& Oliveira, R.C. 2012. Paspalum. In: Lista das espécies da flora do Brasil. Jardim Botânico do Rio de Janeiro. Disponível em $<$ http://floradobrasil. jbrj.gov.br/2012/FB013432>. Acesso em 8 Out 2012.

Watson, L. \& Dalwitz, M.F. 1992. The grass genera of the world. Cambridge University Press, Cambridge. $1081 \mathrm{p}$.

Zuloaga, F.O. \& Morrone, O. 2003. Paspalum. In: Catalogue of New World grasses (Poaceae): III. Subfamilies Panicoideae, Aristidoideae, Arundinoideae, and Danthonioideae. Contributions from United States National Herbarium 46: 443-527.

Zuloaga, F.O. \& Morrone, O. 2005. Revisión de las especies de Paspalum para América del Sur austral. Monographs in Systematic Botany from the Missouri Botanical Garden 102: 1-297.

Zuloaga, F.O.; Pensiero, J. \& Morrone, O. 2004. Systematic of Paspalum group Notata (Poaceae-PanicoideaePaniceae). Systematic Botany Monography 71:1-75. 